\title{
SARNA NORUEGA
}

NORWEGIAN SCABIES

Horacio Matías Castro ${ }^{1,3}$, Maite Lisa Eliceche ${ }^{2}$.

\section{Resumen:}

La sarna noruega es una forma especial de escabiosis, infección cutánea producida por el Sarcoptes scabiei, infrecuente y muy contagiosa que afecta principalmente a pacientes inmunodeprimidos, ancianos e institucionalizados. Se presenta con una erupción eritematosa con costras y placas hiperqueratósicas en manos, pies, cara, cuero cabelludo y el tronco. El objetivo del trabajo es mostrar las lesiones cutáneas características de esta patología, su diagnóstico y tratamiento.

Palabras clave: sarna noruega; diagnóstico; tratamiento.

\section{Abstract:}

Crusted scabies is a clinical variant of classical scabies, which is an infestation of the skin by the mite Sarcoptes scabie, Infrequent with high mite burden, usually in people with reduced cellular immunity or elderly long-term care residents. Cutaneous findings are erythematous patches, with prominent scales, usually located in hands, feet, scalp, face and trunk. The aim of this report is to describe dermatological findings of this clinical variant, the diagnosis and treatment.

Keywords: scabies; diagnosis; therapeutics. 


\section{Caso Clínico}

Mujer de 87 años procedente de una residencia de ancianos, con deterioro cognitivo, que consultó por una erupción cutánea (fig. 1) pruriginosa de 4 meses de evolución, acompañada de costras y placas hiperqueratósicas en cuero cabelludo, plantas y palmas (fig. 2). En el escarificado directo de las costras se observó, a través del microscopio utilizando una tinción de hidróxido de potasio al 10\%, la morfología del sarcoptes. Por lo que se llegó al diagnóstico de Sarna noruega. La paciente fue tratada con ivermectina oral junto con permetrina al 5 \% tópica, y evolucionó con resolución completa de las lesiones. Los contactos fueron tratados con ivermectina oral.
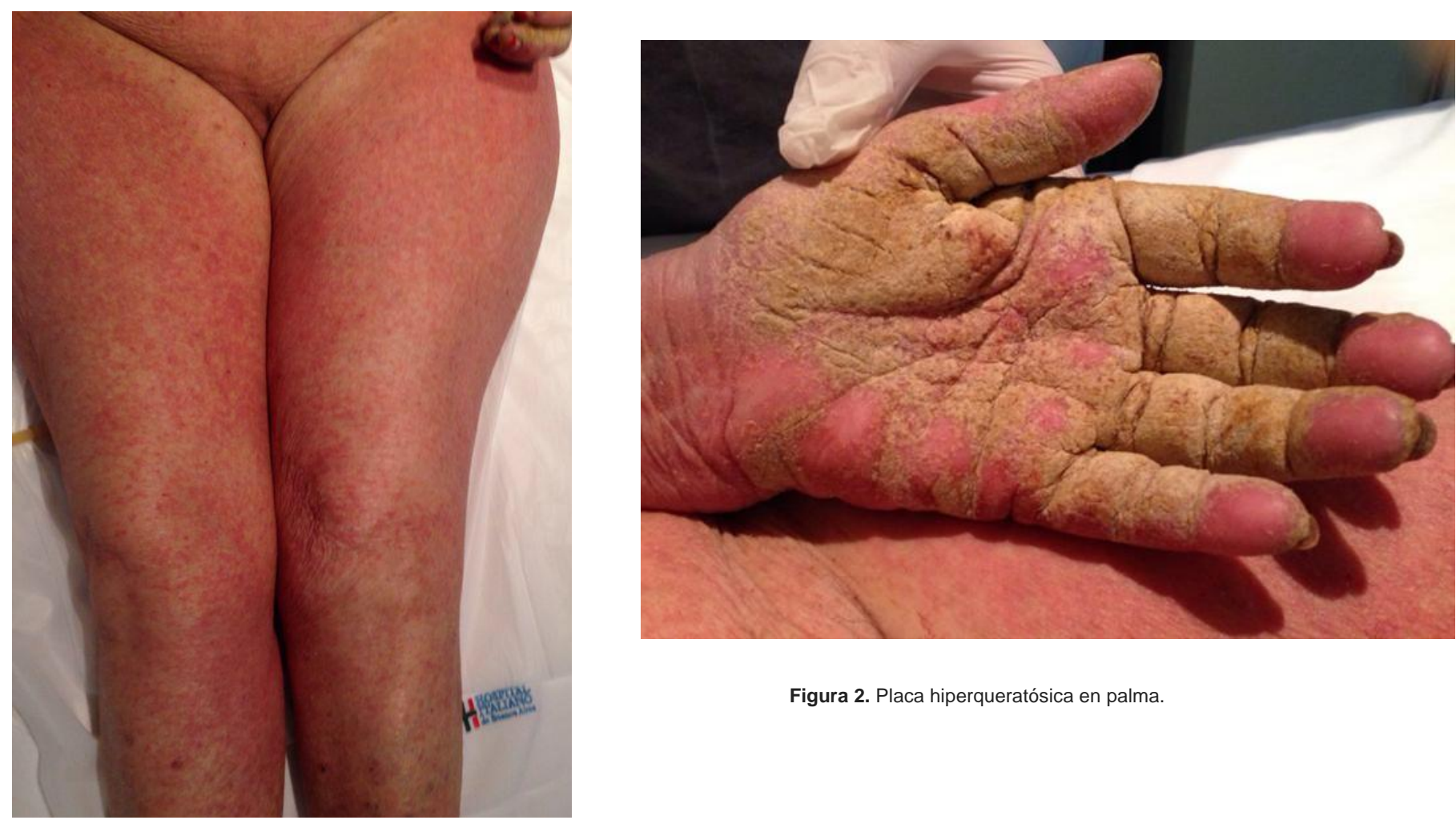

Figura 2. Placa hiperqueratósica en palma.

Figura 1. Erupción morbiliforme en miembros inferiores.

La sarna noruega o costrosa es una forma especial de escabiosis que fue descripta inicialmente por Danielssen y Broca en pacientes con lepra, en Noruega en 1848. Es una infección cutánea producida por el Sarcoptes scabiei, infrecuente y muy contagiosa que afecta principalmente a pacientes inmunodeprimidos, institucionalizados, con deterioro cognitivo y ancianos ${ }^{1}$. La principal fuente de transmisión es por contacto directo con la piel de una persona infectada o por transmisión indirecta por la alta carga parasitaria ${ }^{2}$. Se presenta como erupción eritematosa pruriginosa acompañada de costras y placas hiperqueratósicas con una distribución característica en manos, pies, cara, cuero cabelludo y el tronco. El principal síntoma es el prurito generalizado a predominio nocturno. El diagnóstico se establece a través del examen físico que evidencie la distribución típica de la lesiones cutáneas ${ }^{1}$ y la confirmación con una prueba diagnóstica ${ }^{3}$ en nuestro caso el escarificado.

Si bien el tratamiento no se encuentra estandarizado se decidió seguir las recomendaciones del Centro de Control y Prevención de Enfermedades de Estados Unidos que consisten en realizar tratamiento combinado con permetrina tópica al $5 \%$ diario por 7 días y luego 2 veces semanales hasta la resolución junto con ivermectina vía oral $(200 \mathrm{mcg} / \mathrm{kg} / \mathrm{dosis})$ suministrada en los días $1,2,8,9$, y $15^{4}$. Deben tratarse a los contactos estrechos de los pacientes afectados.

Es importante la sospecha clínica para realizar el diagnóstico e instaurar el tratamiento oportuno, con el fin de evitar complicaciones y acortar el ciclo de contagio.

\section{Bibliografía}

1. Shimose L, Munoz-Price L. Diagnosis, prevention, and treatment of scabies. Curr Infect Dis Rep. 2013;15(5):426-431.

2. Chosidow O. Scabies. N Engl J Med. 2006;354(16):1718-1727.

3. Leung V, Miller M. Detection of scabies: a systematic review of diagnostic methods. Can J Infect Dis. 2011;22(4):143-146.

4. Workowski KA BG. Centers for Disease Control and Prevention. Sexually transmitted diseases treatment guidelines. MMWR Recomm Rep 2015;64(1). 